\title{
Providing a Model for Predicting the Financial Behavior of Investors in the Iranian Stock Market
}

\author{
Sallar Ashqi Kareem ${ }^{1}$ \\ ${ }^{1}$ Department of Accounting, Faculty of Administrative Sciences, Tishk International University, Erbil, Iraq \\ Correspondence: Sallar Ashqi Kareem, TIU, Department of Accounting, Erbil, Iraq. \\ Email: sallar.ashqi@tiu.edu.iq
}

Doi: 10.23918/ejmss. v1i3p20

\begin{abstract}
The pattern of investor behavior in the stock market is a complex process that is influenced by many factors such as Personality, culture, behavioral patterns, emotional and cognitive biases. The purpose of this study is to provide a model for predicting the financial behavior of investors in the Iranian stock market. In order to achieve the objectives of this study, the necessary data were collected in a time period during 2019-2020 spring. Then fuzzy analysis method was used to analyze the data. The results showed that the self-attribution criterion with a weight of 0.107 is in the first priority, the criterion of remorse with a weight of 0.099 is in the second priority and finally the criterion of increasing risk with a weight of 0.094 is in the third priority.
\end{abstract}

Key words: financial behavior, stock market, investors, predicting

\section{Introduction}

Since the recognition of the finite attention theory (Kahneman, 1973; Pashler et al., 2001), how investors pay attention and investor behavior to the stock market and its associated effects has increasingly attracted the attention of academics (For example, Kerwin and Kognor 2008; Da et al., 2011; Takeda and Wakao, 2014; Huang et al., 2019; Ramos et al., 2020). The purpose of this paper is to examine the dynamic relationship between retail investor attention and stock liquidity In Tehran Stock Exchange in a time period during 2019-2020 spring. Stock liquidity is often referred to as the speed and convenience of investors in stock trading without drastically changing its price (Chen et al., 2021). As a sign of stock market efficiency, investor behavior is directly related to this efficiency. Numerous studies (e.g., Barber and Odin (2008), Avadi et al. (2013), Takeda and Wakao (2014), Ding and Hoo (2015), Adachi et al. (2017), and Wang et al. (2018)) they said that investor attention has a positive short-term effect on stock liquidity.In this way, according to the stock market investors, the amount of exchanges and purchases and subscriptions increases and as a result, the amount of stock liquidity increases for a short period of time. However, first, focusing on the short-term impact of investor attention on the stock market, the above studies use horizons shorter than one week and affect the strength of forecasts (Cheng et al., 2021).

However, in financial processes, there are often situations that break the rules and make it difficult to predict by these methods. There are various methods of prediction in the subject literature. The main question of the research refers to the extent to which financial variables and variables affected by the behavior of investors affect the stock price and on the other hand due to the nonlinearity of financial time series which is a challenge to predict and also affect the general public. The current problem in the Tehran Stock Exchange is the lack of proper knowledge of the behavioral factors affecting investors' investment decisions (both real and institutional). This lack of correct knowledge causes the efficiency of the market to decrease and financial resources to not be properly equipped and allocated, and ultimately leads to a waste of resources in this market, because in this case resources enter the main channels that create efficiency in the market. , Have not; Therefore, in addition to developing financial and behavioral knowledge in the country, understanding these factors can help investors become familiar with the biases they inadvertently face in making their investment decisions, and also help stock market officials in setting the rules and regulations that the market Helps to stabilize the balance and thus prevent the occurrence of anomalies such as price bubbles in the stock market in recent years. Ignoring the role and influence of behavioral factors in decision making by investors, which is highly regarded in the world financial markets today as one of the theories in the field of investment and has not found its place among other theories, can be considered harmful. Financial time series predictions that these influencing factors themselves can be variables with separate time series and also the importance of selecting the best examples in the forecasting process by different models. Can a model be provided to increase the accuracy of such 
predictions by considering the influencing factors? Therefore, the present study pursues the following scientific objectives:

$\checkmark$ Explain the selection of the best examples as well as the effective commons in forecasting financial time series with the aim of increasing the accuracy of forecasts

$\checkmark \quad$ Investigating and comparing the behavioral factors of Tehran Stock Exchange investors by considering the stock price forecast of the company along with other commons, including avoiding regret and remorse.

\section{Theoretical foundations}

All managers deal with the decision-making process. In fact, decision-making and management can be considered synonymous, because decision making is a key component of management. That is why knowing the decision is so important. Investment requires the study of the investment process and the management of shareholders' wealth, and the investment process, in a coherent manner, requires an assessment of the principled nature of investment decisions; therefore, investment decisions should be made based on scientific principles and with due care (Bansal, 2020).

According to Modigliani and Miller's indifference model, in the full market, financing decisions are separate from investment decisions, and despite investment opportunities with a positive net present value, it does not matter where or how the funding comes from; But when there are imperfect markets, there is, in fact, a world outside the indifferent world of Modigliani and Miller (Ayouzian et al., 2005).

"Given that many factors affect the behavior of investors, there is an empirical challenge to analyze the impact of investor behavior and net normalize the business activities of investors. Some research suggests that gender and age can explain some of the changes in investor behavior, although the effects vary in different countries and regions (Hasu et al., 2020). Most experimental work on investor attention follows the principles set out in Merton (1987) or The Price Pressure Hypothesis proposed by Barber et al. (2008). The second hypothesis is that the increase in stock prices and liquidity is due to increased investor attention. The authors also argue that choosing the best stock is not easy because there are thousands of stocks and investors need to choose for a limited time and they only choose the stock that gets the most attention. Individual investors in most cases do not face this problem when selling a stock that they already owned and are aware of ( $\mathrm{Lu}$ and Cho, 2012). Conversely, institutional investors are usually immune to this problem because they usually have access to the tools needed for analysis. In addition, corporate investors typically sell short compared to individual investors and are known to engage in online search activity before choosing the best stock and committing to making an investment decision (e.g., buying or selling stocks). They do a wide range. Experimental testing of the subject from different markets leads to different insights into the possible links between information retrieval and stock prices or stock returns. A recent study by Sami et al. (2019) used the quantitative regression method in Indian stock market data from 2012 to 2017. The authors show that repeated searches for stock information are associated with higher returns in the first and second weeks of investment. In addition, this study also suggests that when the asset undergoes a moving stage, there is a strong correlation between investor behavior and stock returns. Previously, Goddard et al. (2015) found that market index returns, volatility, and trading volume have strong causal relationships. They also stated that one of the effective factors for predicting stock market fluctuations is the study of the behavior pattern of investors. Scientists consider the role of psychological factors in investor trading decisions and stock prices in financial behavior. A number of them have focused on the impact of real air quality on the stock market (Tang and Hee, 2020). Evidence from several countries, including the United States, Spain and Germany, shows that various factors have a negative impact on investor behavior and then they returned. They found that the relationship between behavioral patterns and stock returns was significant in the period 2005-2014, but this relationship has grown significantly in recent years. They explain that increasing public awareness of financial issues, as well as increasing information published by company owners, shapes the emotional reactions and behaviors of investors to buying stocks and affects stock returns".

\section{Research methodology}

In terms of purpose, this research is among the applied research. The necessary data for this study have been collected from the Tehran Stock Exchange cross-sectionally in the spring period of 2020-2019. To analyze the data and achieve the research objectives of the quantitative data analysis method. Then data was analysis with fuzzy analysis method. In the fuzzy hierarchical analysis method, after preparing the hierarchical diagram, the decision maker or decision 
maker is asked to construct the elements of each level relative to each other and to express the other relative elements using Fuazzy numbers.

\section{Analysis of findings}

In the analysis stage, the important point is that the researcher must direct and analyze the information and data in the direction of the goal, answering the research question or hypotheses, as well as evaluation. In decision science, in which the choice of a solution from among the existing solutions or the prioritization of solutions is discussed, decision-making methods with multiple criteria or MCDM have been in place for several years. In such decisions, several indicators or goals that are sometimes contradictory are considered. If multi-criteria decision making (MCDM) refers to the benchmark criterion, it is known as multiple-criteria decision making (MADM). MADM models are used to select the most appropriate option from the available $\mathrm{M}$ options. This model often used in cases where in specific issues with several different indicators, including quantitative and qualitative indicators such as: cost, degree of importance, capacity, longevity, national reputation, etc. are faced simultaneously and the purpose of the problem in Considering all these indicators simultaneously and finding an option in which the outcome of the desirability of these indicators is maximized. But if multi-criteria decision-making refers to the goal, it is called multi-objective decision making (MODM). In this model several goals are considered simultaneously for optimization. The scale for each goal may be different from the scale for the other goals One of the first multi-criteria decision making (MADM) methods is the Analytic Hierarchy Process (AHP) which has been used more than other methods in management science. In this research, multi-criteria decision models and FAHP model have been used to identify the relationships and determine the priority of the indicators of the present study.

\section{$\checkmark \quad$ Identify the final indicators}

The main criteria of the present study are cognitive bias, emotional bias, cultural factors. Cognitive bias means Biases, errors, deviations, and individual and innovative methods that are created in the process of understanding the phenomena (stocks, buying and selling offers, etc.). Because the source of the cognitive inclination of the argument is incorrect, more information and counseling can often correct it. Emotional bias Biases, errors, deviations and individual and innovative methods in the process of emotional labeling in relation to the consequences of actions, their justification, etc., in relation to decisions and phenomena Is created (stocks, sales offers, market trends, etc.) (Abdul Rahimian et al.,2016). For each of these criteria, indicators have been considered so that a total of 13 subcriteria have been selected. The criteria and sub-criteria of the research are listed in Table 1. Also, the criteria and subcriteria of the research with numerical index are named as Table 1 so that it can be easily traced and studied during the research.

Table 1- Main indicators and related sub-criteria

\begin{tabular}{cccc}
\hline symbol & The main criterion & symbol & under the criteria \\
\hline $\mathrm{C} 1$ & Cognitive biases & $\mathrm{S} 11$ & Familiarity \\
\cline { 3 - 3 } & & $\mathrm{S} 12$ & Limited attention \\
\cline { 3 - 3 } & & $\mathrm{S} 13$ & Self-reported \\
\cline { 3 - 3 } & & $\mathrm{S} 14$ & Reliance point \\
\cline { 3 - 3 } & & $\mathrm{S} 15$ & Cross-confidence \\
\hline $\mathrm{C} 2$ & Emotional biases & $\mathrm{S} 21$ & Damage \\
\cline { 3 - 3 } & & $\mathrm{S} 22$ & Increasing risk \\
\cline { 3 - 3 } & & $\mathrm{S} 23$ & Justification \\
\hline
\end{tabular}




\begin{tabular}{cccc}
\hline & & S24 & Optimism \\
\cline { 3 - 3 } & & S25 & Regret remorse \\
\hline C3 & cultural factors & S31 & time horizon \\
\cline { 3 - 3 } & & S32 & Locus of control \\
\cline { 3 - 3 } & & S33 & Tolerance of ambiguity \\
& &
\end{tabular}

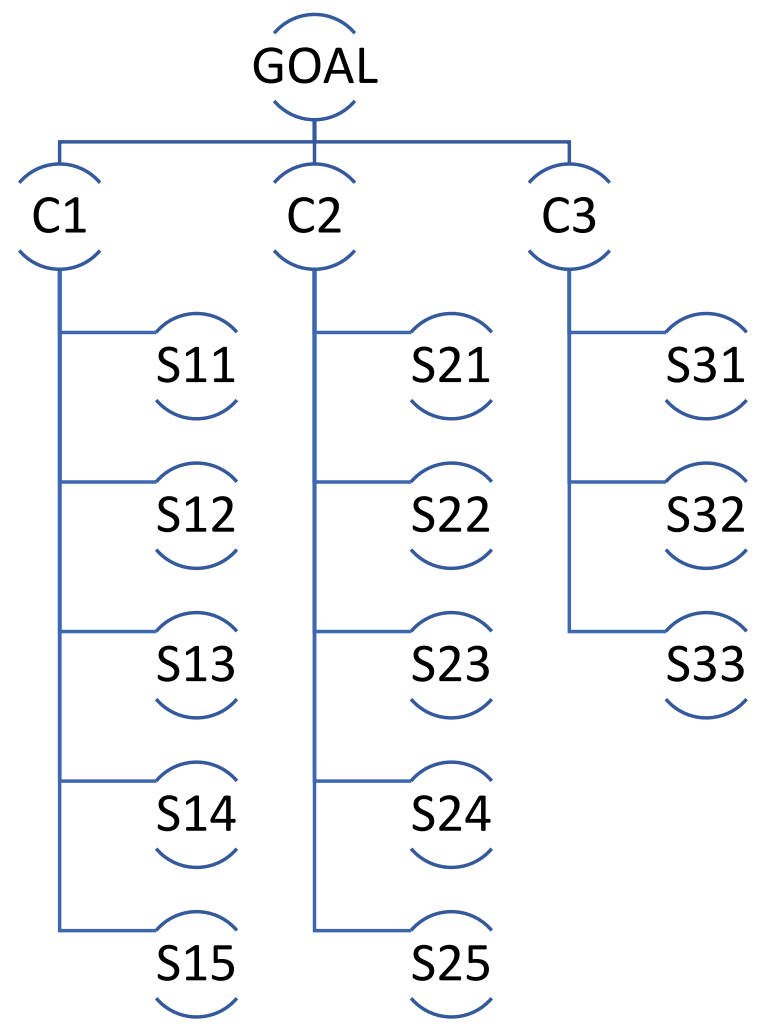

Figure 1- Hierarchical pattern of criteria and sub-criteria

\section{Prioritize the main criteria}

Fuzzy hierarchical analysis technique has been used to prioritize the main criteria. The analysis process is as follows:

1- Parallel comparison of the main criteria based on the purpose and determining the weight of the main criteria

2- Pair comparison of sub-criteria of each criterion and determining the weight of sub-criteria of each cluster

A nine-degree scale was used to compare pairs of elements. The nine-hour scale was proposed by Thomas Saati, the author of the theory of hierarchical analysis. The fuzzy approach is also used in this study to quantify the values. Therefore, the fuzzy clock spectrum is used. 


\section{EJMSS Eurasian Journal of Management \& Social Sciences}

Table 2 - Scale of linguistic variables with fuzzy triangular numbers, sun and zabihi, 1389: 41; Lee et al., 2008: 101

\begin{tabular}{clcccccc}
\hline Value & Comparison status of i with j & \multicolumn{2}{c}{ Fuzzy numbers } & \multicolumn{2}{c}{ Inverse fuzzy numbers } \\
\cline { 3 - 7 } & & $\mathrm{u}$ & $\mathrm{m}$ & 1 & $\mathrm{u}$ & $\mathrm{m}$ & $\mathbf{l}$ \\
\hline 1 & Equally Preferred & 1 & 1 & 1 & 1 & 1 & $\mathbf{1}$ \\
\hline 2 & Between & 3 & 2 & 1 & 1 & 0.5 & $\mathbf{0 . 3 3 3}$ \\
\hline 3 & moderately Preferred & 4 & 3 & 2 & 0.5 & 0.333 & $\mathbf{0 . 2 5}$ \\
\hline 4 & Between & 5 & 4 & 3 & 0.333 & 0.25 & $\mathbf{0 . 2}$ \\
\hline 5 & Strongly Preferred & 6 & 5 & 4 & 0.25 & 0.2 & $\mathbf{0 . 1 6 6}$ \\
\hline 6 & Between & 7 & 6 & 5 & 0.2 & 0.16 & $\mathbf{0 . 1 4 2}$ \\
\hline 7 & Very strongly Preferred & 8 & 7 & 6 & 0.166 & 0.142 & $\mathbf{0 . 1 2 5}$ \\
\hline 8 & Between & 9 & 8 & 7 & 0.142 & 0.125 & $\mathbf{0 . 1 1 1}$ \\
\hline 9 & Extremely Preferred & 9 & 9 & 9 & 0.111 & 0.111 & $\mathbf{0 . 1 1 1}$
\end{tabular}

\section{$\checkmark \quad$ Prioritize key factors based on purpose}

In the first step, the main criteria are compared based on the goal in pairs. Pair comparison is very simple, and all elements of each cluster should be compared in pairs. $\frac{n(n-1)}{2}$ Therefore, if there are $\mathrm{n}$ elements in a cluster, a comparison will be made. Because there are 3 criteria, so the number of comparisons made is equal to:

$$
\frac{n(n-1)}{2}=\frac{3(3-1)}{2}=3
$$

Therefore, 3 pairwise comparisons were performed from the perspective of a group of experts. Experts' views have been quantified using the fuzzy scale. Expert opinion collection with a range of nine degrees is collected. The fuzzy view of experts is based on Table 2. Therefore, 3 pairwise comparisons for the main criteria based on the experts' point of view have been done fuzzily.

- Aggregation of experts 'point of view: It is better to use the geometric mean of each of the three triangular fuzzy numbers to aggregate the experts' point of view.

$$
F_{A G R}=\left(\prod(l), \prod(m), \prod(u)\right)
$$

Using the fuzzy geometric mean of the experts' point of view, the pairwise comparison matrix is shown in Table 3 . 


\section{EJMSS Eurasian Journal of Management \& Social Sciences}

Table 3- Parallel comparison matrix of main criteria

\begin{tabular}{|c|c|c|c|c|c|c|c|c|c|}
\hline & \multicolumn{3}{|c|}{ C1 } & \multicolumn{3}{|c|}{ C2 } & \multicolumn{3}{|c|}{ C3 } \\
\hline C1 & 1 & 1 & 1 & 1.881 & 1.599 & 1.347 & 2.683 & 2.176 & 1.672 \\
\hline $\mathrm{C} 2$ & 0.742 & 0.626 & 0.532 & 1 & 1 & 1 & 4.294 & 3.508 & 2.722 \\
\hline C3 & 0.598 & 0.459 & 0.373 & 0.367 & 0.285 & 0.233 & 1 & 1 & 1 \\
\hline
\end{tabular}

After forming the matrix of paired comparisons, the special vector is calculated. First, the fuzzy sum of each row is calculated.

$$
\sum_{\mathrm{j}=1}^{n} \mathrm{M}_{\mathrm{g}}^{\mathrm{j}}
$$

Then the fuzzy sum of the elements of the column of preferences is calculated:

$$
\sum_{i=1}^{\mathrm{n}} \sum_{j=1}^{\mathrm{n}} M_{g}^{j}
$$

To normalize the preferences of each criterion, the sum of the values of that criterion must be divided by the sum of all the preferences (column elements). Because the values are fuzzy, the fuzzy sum of each row is multiplied by the inverse of the sum. The inverse of the sum must be calculated.

$\mathrm{F}_{1}^{-1}=\left(1 / \mathrm{u}_{1}, 1 / \mathrm{m}_{1}, 1 / \mathrm{l}_{1}\right)$

$\mathrm{S}_{k}=\sum_{i=1}^{n} M *\left(\sum_{i=1}^{\mathrm{n}} \sum_{j=1}^{\mathrm{n}} M_{g}^{j}\right)^{-1}$

Therefore, the results of normalization of the obtained values will be as follows:

\begin{tabular}{ccc}
\hline \multicolumn{3}{c}{ Normal } \\
\hline 0.296 & 0.410 & 0.563 \\
\hline 0.314 & 0.441 & 0.661 \\
\hline 0.118 & 0.150 & 0.199 \\
\hline
\end{tabular}

Each of the obtained values of fuzzy and normalized weight corresponds to the main criteria. There are methods such as the Murkowski method for decaphasizing the obtained values. In this study, the calculations of the center of gravity method for fuzzy decoupling have been used.

$$
\begin{aligned}
& x_{\max }^{1}=\frac{l+m+u}{3} \\
& x_{\max }^{3}=\frac{l+2 m+u}{4}
\end{aligned}
$$




\section{EJMSS Eurasian Journal of Management \& Social Sciences}

$x_{\max }^{2}=\frac{l+4 m+u}{6}$

Crisp number $=Z^{*}=\max \left\{x_{\max }^{1}, x_{\max }^{2}, x_{\max }^{3}\right\}$

Finally, the de-fuzzy value is transferred to the final fuzzy hierarchical analysis to determine the weight of the criteria. It should be noted that the calculated weights are non-fuzzy but should be normalized.

Table 4 - De-fuzzy weight values of the main criteria

\begin{tabular}{cccccc}
\hline Crisp & X1max & X2max & X3max & Deffuzy & Normal \\
\hline C1 & 0.187 & 0.186 & 0.185 & 0.187 & 0.182 \\
\hline C2 & 0.208 & 0.207 & 0.206 & 0.208 & 0.203 \\
\hline C3 & 0.270 & 0.269 & 0.268 & 0.270 & 0.263 \\
\hline
\end{tabular}

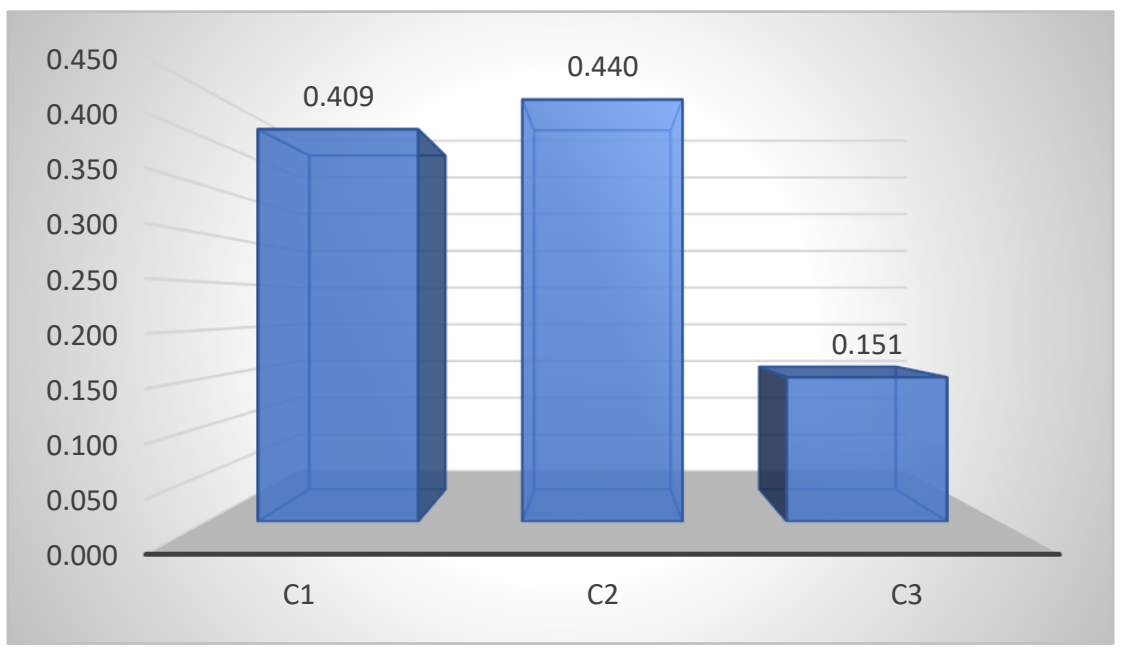

Figure 2 - Prioritization of the main criteria of the research

Accordingly, the special vector of priority of the main criteria will be W1.

$\mathrm{W}_{1}=\left(\begin{array}{c}0.440 \\ 0.409 \\ 0.151\end{array}\right)$




\section{EJMSS Eurasian Journal of Management \& Social Sciences}

Based on the special vector obtained:

A) Emotional bias with a normal weight of 0.440 has the highest priority.

B) Cognitive biases with a normal weight of 0.409 are in the second degree.

C) Cultural factors with a normal weight of 0.151 are in the third degree.

The consistency rate of the comparisons is 0.004 , which is less than 0.1 , so the comparisons can be trusted.

\section{$\checkmark \quad$ Prioritize research sub-criteria}

In the second step of the FAHP technique, the related sub-criteria are compared in pairs. The pairwise comparison of each cluster is examined separately. Due to the length of fuzzy calculations and the similarity of the steps taken to determine the priority of each of the sub-criteria of this study, their repetition in this section has been omitted. In the following, the priority of the sub-criteria of each cluster is shown as follows.

\section{$\checkmark$ Pair comparison of sub-criteria of cognitive bias}

Fuzzy values of the average view of experts to determine the priority of the sub-criteria of cognitive bias are presented in Table 5.

Table 5 - Prioritization of sub-criteria of cognitive bias

\begin{tabular}{lcccccccccccccccc} 
& \multicolumn{3}{c}{ S11 } & \multicolumn{3}{c}{ S12 } & \multicolumn{3}{c}{ S13 } & \multicolumn{3}{c}{ S14 } & \multicolumn{3}{c}{ S15 } \\
\hline S11 & 1.00 & 1.00 & 1.00 & 1.07 & 1.30 & 1.58 & 0.54 & 0.65 & 0.78 & 0.74 & 0.88 & 1.03 & 0.91 & 1.12 & 1.33 \\
\hline S12 & 0.63 & 0.77 & 0.93 & 1.00 & 1.00 & 1.00 & 1.83 & 2.09 & 2.36 & 0.72 & 0.77 & 0.83 & 0.72 & 0.91 & 1.15 \\
\hline S13 & 1.28 & 1.55 & 1.84 & 0.42 & 0.48 & 0.55 & 1.00 & 1.00 & 1.00 & 1.58 & 1.70 & 1.87 & 1.80 & 2.45 & 3.06 \\
\hline S14 & 0.97 & 1.13 & 1.34 & 1.21 & 1.31 & 1.38 & 0.53 & 0.59 & 0.63 & 1.00 & 1.00 & 1.00 & 0.70 & 0.82 & 0.98 \\
\hline S15 & 0.75 & 0.90 & 1.09 & 0.87 & 1.10 & 1.38 & 0.33 & 0.41 & 0.56 & 1.43 & 1.23 & 1.43 & 1.00 & 1.00 & 1.00
\end{tabular}

Table 6- De-fuzzy values under the cognitive bias criteria

\begin{tabular}{cccccc}
\hline Crisp & X1max & X2max & X3max & Deffuzy & Normal \\
\hline S11 & 0.187 & 0.186 & 0.185 & 0.187 & 0.182 \\
\hline S12 & 0.208 & 0.207 & 0.206 & 0.208 & 0.203 \\
\hline S13 & 0.270 & 0.269 & 0.268 & 0.270 & 0.263 \\
\hline S14 & 0.181 & 0.181 & 0.180 & 0.181 & 0.177 \\
\hline S15 & 0.180 & 0.178 & 0.176 & 0.180 & 0.175 \\
\hline
\end{tabular}




\section{EJMSS Eurasian Journal of Management \& Social Sciences}

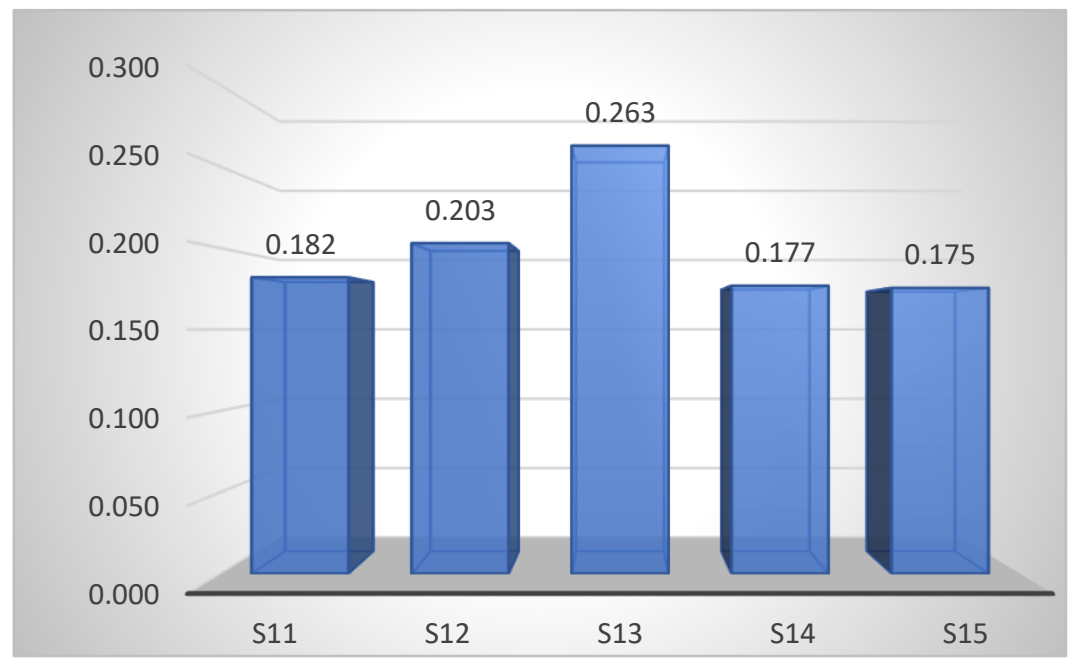

Figure 3 - Prioritization of sub-criteria of cognitive biases

Based on the special vector obtained:

The self-assessment criterion weighing 0.263 has the highest priority.

The meta-confidence criterion with a weight of 0.175 is in the last priority.

The compatibility rate of the comparisons is 0.05 , which is less than 0.1 , so the comparisons can be trusted.

\section{4-2. Pair comparison of sub-criteria of emotional methods}

Fuzzy values are calculated as the average of the experts' point of view to prioritize the sub-criteria of emotional bias.

Table 7- Prioritization of sub-criteria of emotional methods

\begin{tabular}{|c|c|c|c|c|c|c|c|c|c|c|c|c|c|c|c|}
\hline & & S21 & & & S22 & & & $\mathbf{S 2 3}$ & & & S24 & & & S25 & \\
\hline S21 & 1.00 & 1.00 & 1.00 & 1.05 & 1.20 & 1.38 & 0.98 & 1.17 & 1.43 & 0.47 & 0.56 & 0.67 & 0.38 & 0.45 & 0.54 \\
\hline S22 & 0.72 & 0.83 & 0.95 & 1.00 & 1.00 & 1.00 & 2.05 & 2.37 & 2.69 & 0.78 & 0.87 & 0.98 & 0.64 & 0.80 & 1.01 \\
\hline S23 & 0.70 & 0.85 & 1.02 & 0.37 & 0.42 & 0.49 & 1.00 & 1.00 & 1.00 & 1.13 & 1.22 & 1.34 & 1.29 & 1.65 & 2.02 \\
\hline S24 & 1.49 & 1.78 & 2.11 & 1.02 & 1.15 & 1.28 & 0.75 & 0.82 & 0.88 & 1.00 & 1.00 & 1.00 & 0.86 & 1.03 & 1.23 \\
\hline S25 & 1.85 & 2.20 & 2.64 & 0.99 & 1.25 & 1.57 & 0.50 & 0.61 & 0.78 & 1.17 & 0.97 & 1.17 & 1.00 & 1.00 & 1.00 \\
\hline
\end{tabular}

Table 8- De-fuzzy values sub-criteria of emotional methods

\begin{tabular}{cccccc}
\hline Crisp & X1max & X2max & X3max & Deffuzy & Normal \\
\hline S21 & 0.164 & 0.164 & 0.163 & 0.164 & 0.161 \\
\hline S22 & 0.218 & 0.218 & 0.218 & 0.218 & 0.214
\end{tabular}




\section{EJMSS Eurasian Journal of Management \& Social Sciences}

\begin{tabular}{cccccc}
\hline S23 & 0.191 & 0.191 & 0.191 & 0.191 & 0.188 \\
\hline S24 & 0.215 & 0.214 & 0.214 & 0.215 & 0.211 \\
\hline S25 & 0.231 & 0.229 & 0.227 & 0.231 & 0.226 \\
\hline
\end{tabular}

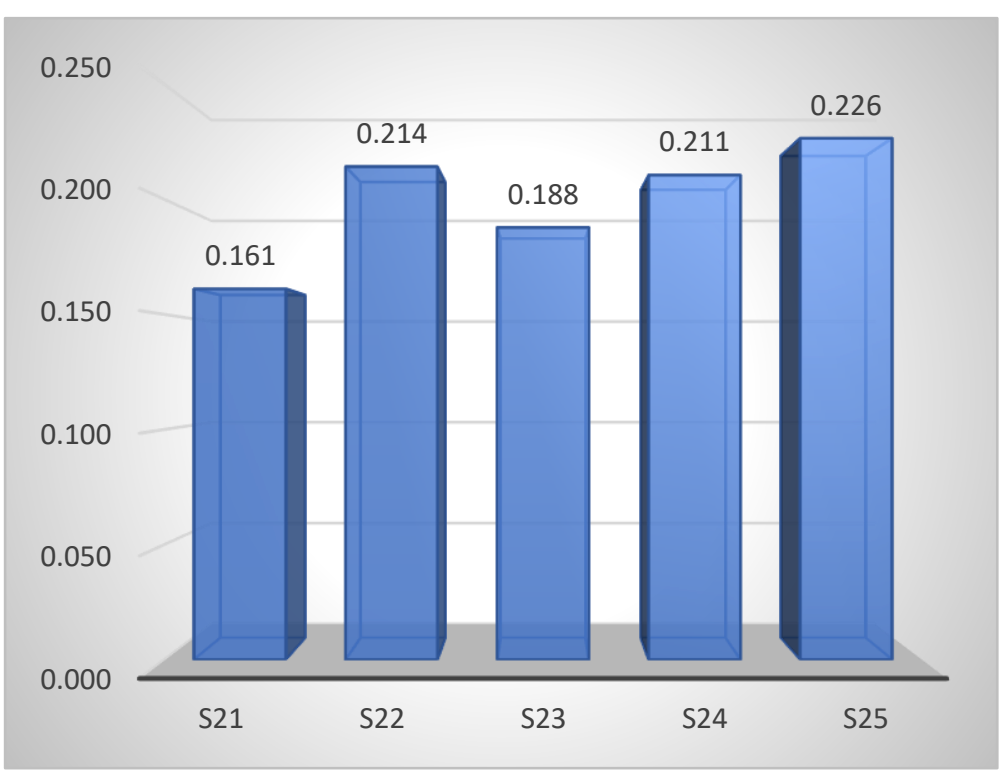

Figure 4 - Prioritization of sub-criteria of emotional methods

Based on the special vector obtained:

Repentance with a weight of 0.226 has the highest priority.

Loss avoidance weighing 0.161 is the last priority.

The compatibility rate of the performed comparisons is 0.07 which is equal to 0.1 and therefore the performed comparisons can be trusted.

\section{4-3. Pair comparison of sub-criteria of cultural factors}

The fuzzy values of the average of the experts' point of view to determine the priority of the sub-criteria of cultural factors are presented in Table 9. Because 3 indicators have been used, so 3 pairwise comparisons have been made.

Table 9 - Determining the priority of sub-criteria of cultural factors

\begin{tabular}{lccccccccc}
\hline & \multicolumn{3}{c}{ S31 } & \multicolumn{3}{c}{ S32 } & \multicolumn{3}{c}{ S33 } \\
\hline S31 & 1.00 & 1.00 & 1.00 & 1.233 & 1.546 & 1.883 & 0.721 & 0.973 & 1.268 \\
\hline S32 & 0.531 & 0.647 & 0.811 & 1.00 & 1.00 & 1.00 & 2.260 & 2.911 & 3.570 \\
\hline S33 & 0.788 & 1.028 & 1.388 & 0.280 & 0.343 & 0.442 & 1.00 & 1.00 & 1.00
\end{tabular}




\section{EJMSS Eurasian Journal of Management \& Social Sciences}

Table 10 - De-fuzzy values under the criteria of cultural factors

\begin{tabular}{cccccc}
\hline Crisp & X1max & X2max & X3max & Deffuzy & Normal \\
\hline S31 & 0.349 & 0.346 & 0.343 & 0.349 & 0.336 \\
\hline S32 & 0.451 & 0.447 & 0.444 & 0.451 & 0.434 \\
\hline S33 & 0.238 & 0.236 & 0.233 & 0.238 & 0.230
\end{tabular}

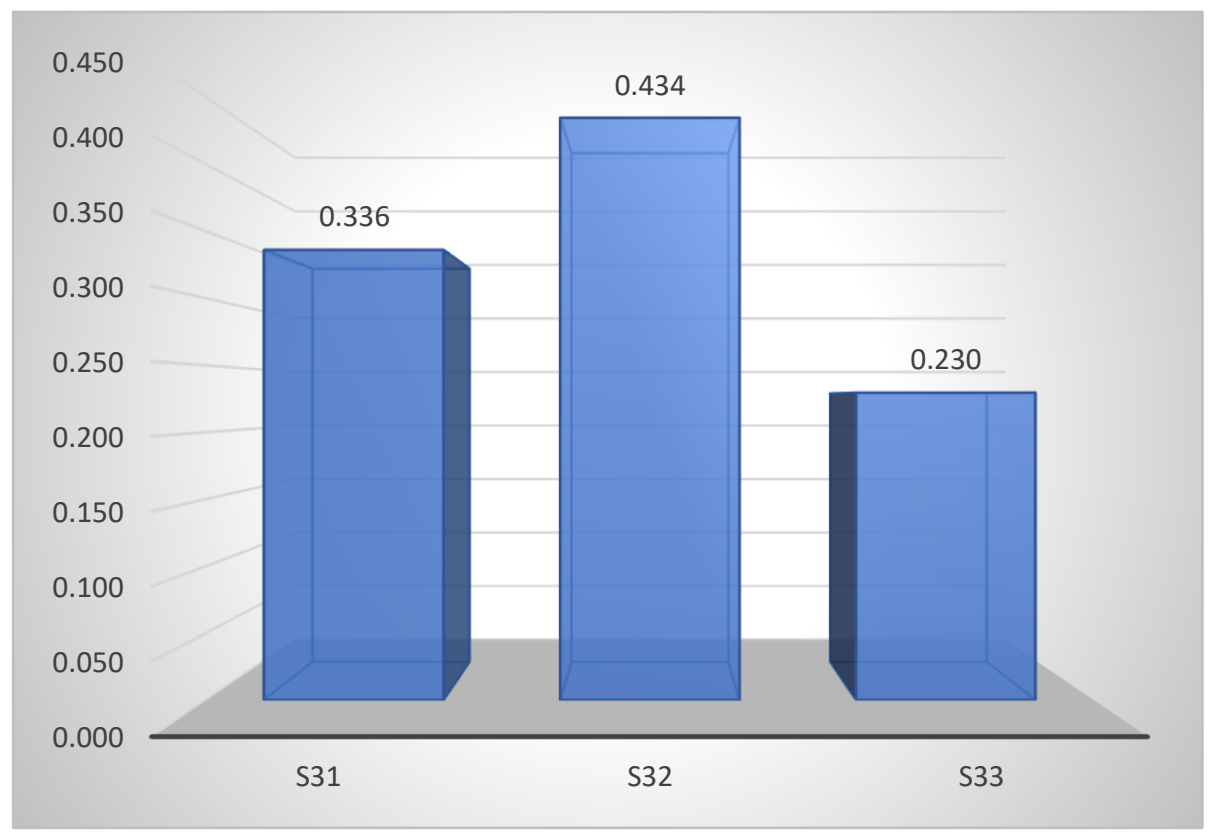

Figure 5 - Prioritization of sub-criteria of cultural factors

Based on the special vector obtained:

The control center with a weight of 0.434 has the highest priority.

The ambiguity tolerance criterion weighing 0.230 is the last priority.

The compatibility rate of the comparisons performed is 0.02 , which is less than 0.1 , and therefore the comparisons made can be trusted.

\section{$\checkmark \quad$ Final priority of indicators with AHP technique}

In this step, the priority is calculated. The results of the comparison of the research sub-criteria and their related weights constitute the $\mathrm{W}_{2}$ matrix. To determine the final priority of the indicators with AHP technique, it is enough to multiply the weight of the indicators based on each criterion $\left(\mathrm{W}_{2}\right)$ by the weight of the main criteria $\left(\mathrm{W}_{1}\right)$. Having 


\section{EJMSS Eurasian Journal of Management \& Social Sciences}

the weight of each of the main criteria $\left(\mathrm{W}_{1}\right)$ and sub-criteria $\left(\mathrm{W}_{2}\right)$, the weight of each of the indicators is calculated. The results of the calculation and the weights related to the indicators are shown in Table 11:

Table 11- Determining the final priority of indicators with AHP technique

\begin{tabular}{|c|c|c|c|c|c|c|}
\hline symbol & $\begin{array}{l}\text { Initial } \\
\text { weight }\end{array}$ & The main criterion & symbol & $\begin{array}{l}\text { Branch } \\
\text { weight }\end{array}$ & Sub-criteria & $\begin{array}{c}\text { Branch } \\
\text { weight }\end{array}$ \\
\hline \multirow[t]{5}{*}{ C1 } & 0.409 & Cognitive biases & S11 & 0.182 & Familiarity & 0.0745 \\
\hline & & & S12 & 0.203 & Limited attention & 0.0831 \\
\hline & & & S13 & 0.263 & Self-reported & 0.1075 \\
\hline & & & S14 & 0.177 & Reliance point & 0.0724 \\
\hline & & & S15 & 0.175 & Cross-confidence & 0.0718 \\
\hline \multirow[t]{5}{*}{$\mathrm{C2}$} & 0.440 & Emotional biases & S21 & 0.161 & Damage & 0.0709 \\
\hline & & & S22 & 0.214 & Increasing risk & 0.0943 \\
\hline & & & S23 & 0.188 & Justification & 0.0826 \\
\hline & & & S24 & 0.211 & Optimism & 0.0927 \\
\hline & & & S25 & 0.226 & Regret remorse & 0.0997 \\
\hline \multirow[t]{3}{*}{$\mathbf{C 3}$} & 0.151 & cultural factors & S31 & 0.336 & time horizon & 0.0506 \\
\hline & & & S32 & 0.434 & Locus of control & 0.0654 \\
\hline & & & S33 & 0.230 & $\begin{array}{c}\text { Tolerance of } \\
\text { ambiguity }\end{array}$ & 0.0346 \\
\hline
\end{tabular}

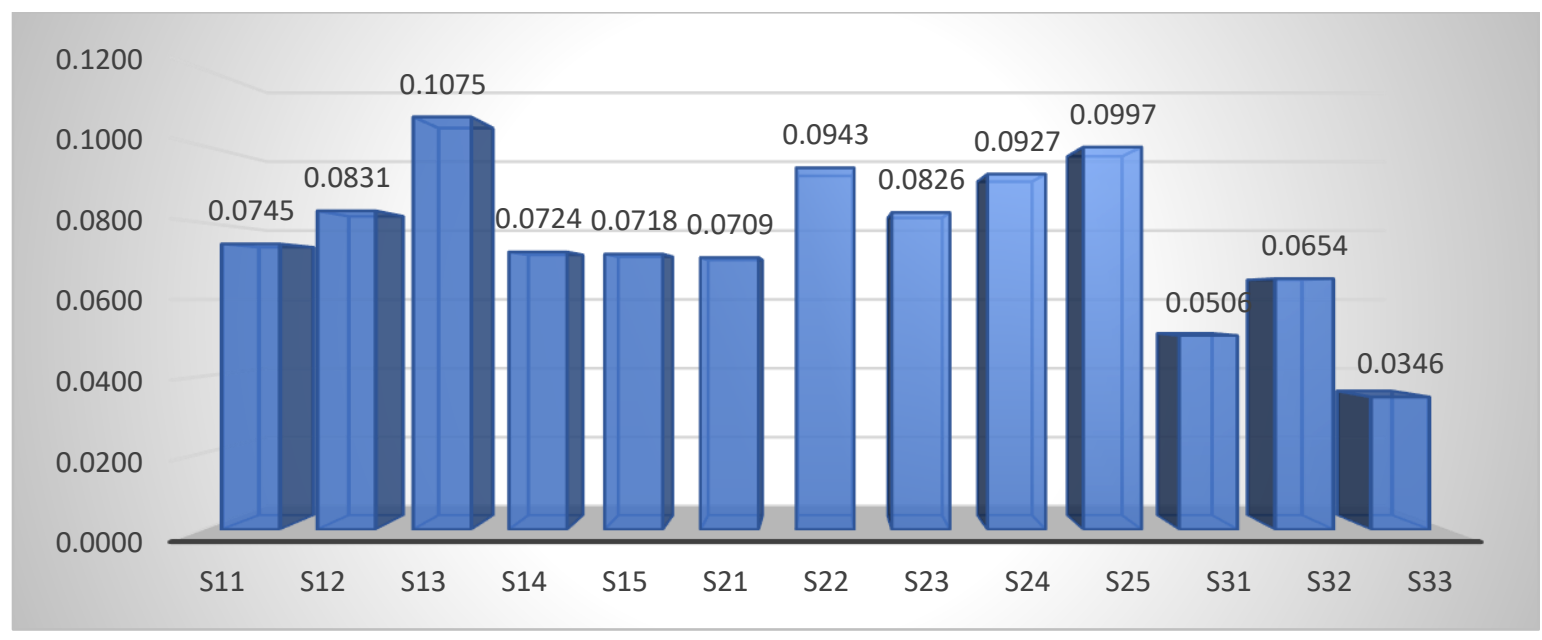

Figure 6- Determining the final priority of indicators with AHP technique 


\section{EJMSS Eurasian Journal of Management \& Social Sciences}

\section{Discussion and Conclusion}

Achieving long-term and continuous economic growth requires optimal equipment and allocation of resources at the level of the national economy, and this is not easily possible without the help of financial markets, especially large and efficient capital markets (Kara et al., 2011). Investing in stocks on the stock exchange is one of the most lucrative options in the capital market. Unknown factors affecting smooth stock price changes are a reason to turn to companies' stock price forecasts (Majdi et al., 2018). The investment behavior of companies listed on the Tehran Stock Exchange, like companies listed on other stock exchanges in the world, is affected by fundamental and financial factors (Kardan et al., 2017). Causal modeling and causal modeling help economists to model relationships comprehensively. Because using a comprehensive model, the behavior of companies can be tested in the presence of various factors (Gard et al., 2015). In research, the variables used are usually limited and linear regressions are used, which have their own limitations. Corporate investment behavior stems from human behavior and decisions, which is more complex than the simple cause-and-effect view found in linear relationships (Van et al., 2020). In this study, the factors used in the test, almost, affected the investment behavior of companies in the forecast. Thus, according to Table 11 and Figure 6 , it was found that:

A) The self-documentation criterion with a weight of 0.107 is in the first priority.

B) The criterion of avoidance with a weight of 0.099 is in the second priority.

C) The criterion of increasing risk with a weight of 0.094 is in the third priority.

The model used in this study is widely used in many aspects of accounting and financial issues such as principled forecasting, classification and modeling. Therefore, it is suitable for investors in the capital market to solve problems that involve learning the relationship between a set of specific inputs and outputs, which is in fact a training technique with the observer to learn the relationship between data using the data set.

Therefore, based on the results obtained in this study, it is suggested for capital market participants:

$>$ A combination of pattern recognition and experience based on observing cause-and-effect relationships and intelligent software programs can be used as a forecasting engine to help make decisions and predict price changes and consequently change investment behavior. To take.

$>$ It is suggested to examine the relationship between personality culture and behavioral biases because personality is influenced by culture.

$>$ It is suggested to investigate the relationship between investors' feelings and behavioral biases and the relationship between information transparency and the occurrence of each of these behavioral factors.

$>$ Factors studied in this study can affect the occurrence of bubbles or falling stock prices as well as the growth of market fluctuations, which can be examined in future research.

\section{References}

Abdolrahmanian, M .H ., Torabi, T., Sadeghi Sharif, J., Darabi, r., (2016), "Presenting the Behavioral Pattern of Real Investors in the Tehran Stock Exchange", Journal of Investment Knowledge, 113-120

Aivazian, V., Ge, Y., Qiu, J., (2005), The impact of leverage on firm Investment:Canadian Evidence. Journal of Corporate Finance, (11), pp. 277-291.

Corwin, S. A., \& Coughenour, J. F. (2008). Limited attention and the allocation of effort in securities trading. The Journal of Finance, 63(6), 3031-3067.

Da, Z., Engelberg, J., \& gao, P. (2011). In search of attention. The Journal of Finance, 66(5), 1461-1499.

Hasso, T., Pelster, M., \& Breitmayer, B. (2020). Terror attacks and individual investor behavior: Evidence from the 2015-2017 European terror attacks. Journal of Behavioral and Experimental Finance, 28, 100397. 


\section{EJMSS Eurasian Journal of Management \& Social Sciences}

Huang, S. Y., Huang, Y. L., \& Lin, T. C. (2019). Attention allocation and return co-movement: Evidence from repeated natural experiments. Journal of Financial Economics, 132, 369-383

Kahneman, D. (1973). Attention and effort (Vol. 1063). Englewood Cliffs, NJ: Prentice-Hall.

Kara, Y.; Boyacioglu, M.A.; Baykan, O.K. (2011). "Predicting direction of stock price index movement using artificial neuralnetworks and support vector machines: The sample of the Istanbul Stock Exchange", Expert Systems with Applications, 38, 5311-5319.

Lepori, G. M. (2016). Air pollution and stock returns: Evidence from a natural experiment. Journal of Empirical Finance, 35, 25-42.

Lu, J., \& Chou, R. K. (2012). Does the weather have impacts on returns and trading activities in order-driven stock markets? Evidence from China. Journal of Empirical Finance, 19(1), 79-93.

Majdi, M.; Ibrahim, A.; Hossam, F.; Abdelaziz, I. H.; Ala, M. A. \& Seyedali, M. (2018). ). "Binary grasshopper optimisation algorithm approaches for feature selection problems", Expert Systems with Applications, 117, 267-286.

Pashler, H., Johnston, J. C., \& Ruthruff, E. (2001). Attention and performance. Annual review of psychology, 52(1), 629-651.

Ramos, S. B., Latoeiro, P., \& Veiga, H. (2019). Limited attention, salience of information and stock market activity. Economic Modelling, 87, 92-108.

Swamy, V., Dharani, M., Takeda, F., 2019. Investor attention and Google Search Volume Index: evidence from an emerging market using quantile regression analysis. Res. Int. Bus. Finance 50, 1-17.

Takeda, F., \& Wakao, T. (2014). Google search intensity and its relationship with returns and trading volume of Japanese stocks. Pacific-Basin Finance Journal, 27, 1-18.

Teng, M., \& He, X. (2020). Air quality levels, environmental awareness and investor trading behavior: Evidence from stock market in China. Journal of Cleaner Production, 244, 118663.

Wen, F., Zou, Q., \& Wang, X. (2020). The contrarian strategy of institutional investors in Chinese stock market. Finance Research Letters, 101845. 